\title{
A Novel Control Method in Flux-weakening Region for Efficient Operation of Interior Permanent Magnet Synchronous Motor
}

\author{
Keitaro Ueda* Student Member, \\ Yukinori Inoue* Member, \\ Shigeo Morimoto*a) Senior Member \\ Masayuki Sanada* Senior Member
}

(Manuscript received Aug. 8, 2014, revised May 18, 2015)

\begin{abstract}
This paper proposes a novel control method in the flux-weakening region. The proposed method utilizes a maximum torque per flux (MTPF) control at full load, and an efficient flux-weakening control at light load. In order to simplify the MTPF control, the approximate method of MTPF curve is proposed. In the flux-weakening control, a more efficient control obtained by minimizing the armature current at light load is applied. In the flux-weakening region, it is possible to operate at the maximum torque by applying the MTPF control. In addition, if the load torque is light, operation along a constant voltage ellipse is more efficient compared to the operation of the MTPF control along the MTPF curve owing to the decrease in copper loss with decreasing armature current. In the proposed efficient flux-weakening control, a current command generation method in which the armature current ampere is adopted for operation along the constant voltage ellipse is also proposed. The validity of the proposed control method is verified by simulation and experimental results.
\end{abstract}

Keywords: IPMSM, Flux-weakening control, High efficiency, MTPF control

\section{Introduction}

The interior permanent magnet synchronous motor (IPM$\mathrm{SM}$ ) is capable of variable speed operation over a wide speed region compared to a surface permanent magnet synchronous motor (SPMSM) ${ }^{(1)}$. This operation is made possible by the flux-weakening control which controls the induced voltage to the induced voltage limit by the negative $d$-axis current in the high speed region. The output capability of PMSM depends on the machine parameters and the control method ${ }^{(1)-(3)}$. The maximum output power can be obtained under the voltage and current constraints by the maximum output control, in which the current vector is operated at the optimal operating condition ${ }^{(3)}$. The profile of the speed versus torque and power characteristics as well as the optimal control method in the high-speed region are dependent on $\Psi_{d \min }\left(=\Psi_{a}-L_{d} I_{a m}\right)^{(1)(3)}$, where $\Psi_{a}$ is the stator flux linkage due to the permanent magnet, $L_{d}$ is the $d$-axis inductance, and $I_{a m}$ is the armature current limit. If $\Psi_{d \min }$ is negative, maximum torque can be obtained in the high-speed flux-weakening region by applying maximum torque per flux (MTPF) control.

The parameter of $\Psi_{d \min }$ is usually positive in the conventional PMSMs. For such PMSMs, in which it is not necessary to apply MTPF control, a lot of flux-weakening strategy has been proposed ${ }^{(4)-(6)}$. In recent years, however, the development of the IPMSM, which uses a smaller amount of, or even no, expensive rare-earth magnet, has progressed ${ }^{(7)-(10)}$. In such PMSMs, $\Psi_{d m i n}$ becomes negative, and thus MTPF

a) Correspondence to: Shigeo Morimoto. E-mail: morimoto@eis. osakafu-u.ac.jp

* Osaka Prefecture University

1-1, Gakuen-cho, Naka-ku, Sakai, Osaka 599-8531, Japan control must be applied at high speeds. However, the method of generating the current command value in the MTPF region is complex ${ }^{(3)}$. The MTPF control strategies were discussed in some papers ${ }^{(11)-(13)}$. In Ref. (11), the flux-weakening control for non-salient pole PMSM having large winding inductance was proposed, however, the control method at the high-speed and light-load condition and the application to the IPMSM drive were not discussed. In general, the control of IPMSM becomes difficult compared with SPMSM. The flux-weakening control strategies including MTPF control for IPMSM were proposed in Refs. (12) and (13). In the control system of Ref. (12), many lookup tables and PI controllers are used for generating the $d$ - and $q$-axis current commands, and the design method of the PI gains is unclear and it will be necessary to adjust those gains appropriately. Therefore, the system configuration and the design of controller seem to be complex. Although the complex control algorithm can be easily implemented with recent high-performance processor, the composition of an easier control system is more preferable to the viewpoint of the easy adjustment of the controller. The direct-flux field-oriented vector control was applied for the MTPF control in Ref. (13). In this system, the current feedback control loop does not exist and voltage commands are generated based on the flux and $q$-axis current. The control method and efficiency characteristics at the highspeed and light-load condition were not discussed in both papers $^{(12)(13)}$.

The purpose of this paper is to develop a novel control method in the flux-weakening region for IPMSM with negative $\Psi_{d m i n}$ in order to achieve a high-efficiency operation $^{(14)}$. The proposed IPMSM drive system is based on the conventional current feedback control, and thus there is 
not additional controller. This paper proposes a generation method of current vector command ( $d$ - and $q$-axis current commands) for improving efficiency and simplifying control system. Because the expression of relations between $d$ and $q$-axis currents for the MTPF control is complicated ${ }^{(3)}$, a straight-line approximation of the MTPF curve is used in order to simplify the control algorithm of the MTPF in the proposed method. In order to achieve high-efficiency operation in the high-speed flux-weakening region, two methods are discussed, and the current vector is operated along a constant-voltage ellipse under the high-speed, light-load condition in the proposed system. The generation method of current vector command is proposed in order to achieve a stable and efficient operation at high speeds. The performances of the proposed control method are evaluated by simulations and experiments, and the validity of the proposed method is verified.

\section{Maximum Output Control}

This section examines the current vector control method used to obtain the maximum output under the limiting voltage and current conditions given as follows:

$$
\begin{aligned}
& V_{o}=\omega \sqrt{\left(\Psi_{a}+L_{d} i_{d}\right)^{2}+\left(L_{q} i_{q}\right)^{2}} \leq V_{o m} \ldots \ldots \ldots \ldots \\
& I_{a}=\sqrt{i_{d}^{2}+i_{q}^{2}} \leq I_{a m} \ldots \ldots \ldots \ldots \ldots \ldots \ldots \ldots \ldots
\end{aligned}
$$

where $V_{o}$ is the induced voltage, $\omega$ is the electrical rotor angular velocity, $\Psi_{a}$ is the armature flux linkage due to permanent magnet, $i_{d}$ and $i_{q}$ are the armature currents in the $d$ - $q$ frame, $L_{d}$ and $L_{q}$ are the $d$ - and $q$-axis inductances, $V_{o m}$ is the induced voltage limit, $I_{a}$ is the armature current, $I_{a m}$ is the armature current limit.

Figure 1 shows the characteristic curves on a current vector plane at 2,000 r/min, where the machine parameters of the tested IPMSM listed in Table 1 are used. The maximum speed of tested IPMSM is limited by $2,000 \mathrm{r} / \mathrm{min}$ due to the limitation of experimental setup, and the control method in the high-speed flux-weakening region is discussed in this

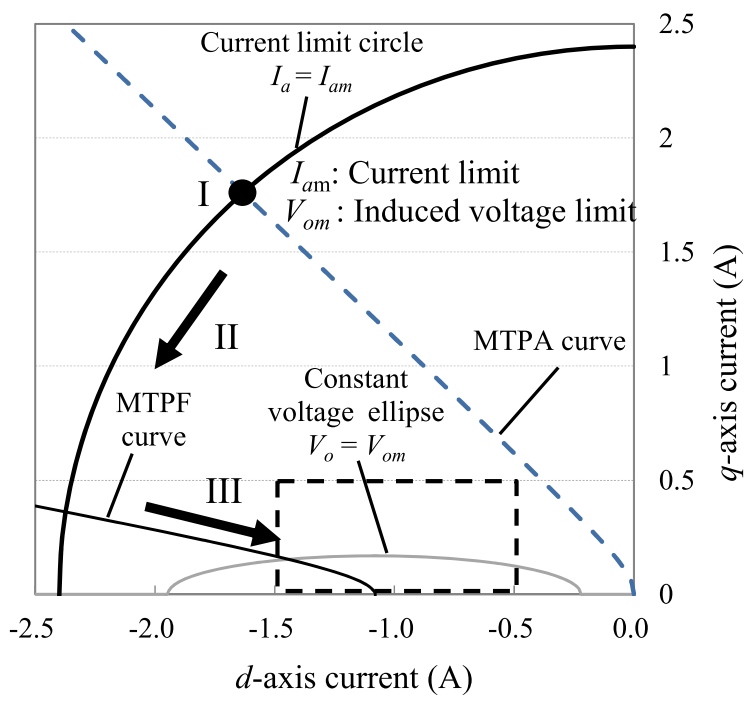

Fig. 1. Characteristic curves on the current vector plane $(2,000 \mathrm{r} / \mathrm{min})$ paper. In order to evaluate the performance in the high-speed flux-weakening region by experiment, the induced voltage limit is set to low value, and thus the base speed becomes $200 \mathrm{r} / \mathrm{min}$ as shown in Table 1 . In this situation, the ratio of voltage drop due to the resistance among the voltage becomes relatively higher. In the proposed current command generation method, however, the armature current limit $I_{a m}$ and the induced voltage limit $V_{o m}$ are considered. Therefore, the voltage drop due to the resistance does not affect the current command generation. The voltage limit due to winding resistance $R_{a}$ is considered when the induced voltage limit $V_{o m}$ is set from the voltage limit $V_{a m} ; V_{o m}=V_{a m}-R_{a} I_{a m}$. In this case, armature voltage $V_{a}$ becomes less than $V_{a m}$ in the control that keeps $V_{o m}$ to $V_{o}$, and there is voltage margin. Although this voltage margin is large in this study because of setting the induced voltage limit to low value as mentioned above, the voltage drop by armature resistance $\left(R_{a} I_{a m}\right)$ is $10 \%$ or less of the voltage limit $\left(V_{a m}\right)$ in general. Thus the voltage margin is not too large and it is thought that the influence of the voltage margin is a little.

The maximum torque per ampere (MTPA) curve and the MTPF curve indicate the current vector trajectory when MTPA control and MTPF control are applied. In Fig. 1, the constant-current limit circle indicates the armature current limit. The constant voltage ellipse indicates the corresponding induced voltage limit at a rotor speed of 2,000 r/min. Figure 2 shows a close-up of the area inside the broken-line rectangle in Fig. 1. Point A is the intersection of the MTPF curve and the constant voltage ellipse. The $q$-axis current on the constant voltage ellipse is maximum at Point B. Points $\mathrm{C}$ and $\mathrm{D}$ are located at the intersection of the constant-torque curve and the characteristic curves, respectively.

2.1 Maximum Torque per Ampere Control Maximum torque per ampere (MTPA) control is performed at the intersection of the current limit circle and the MTPA curve. The MTPA curve is given by the following equation ${ }^{(6)}$.

Table 1. Parameters of the IPMSM and the controller

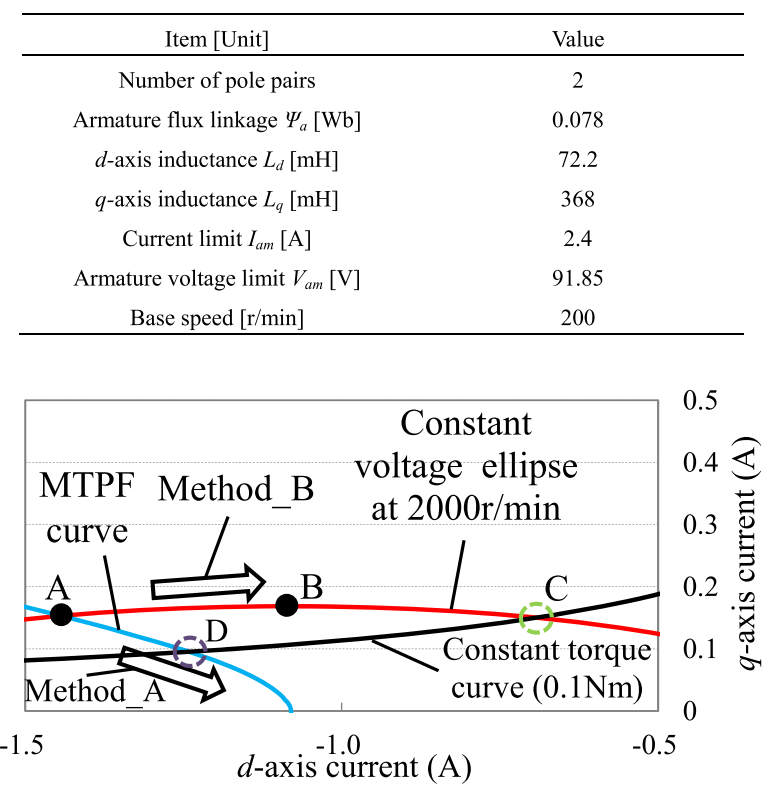

Fig. 2. Close-up of area indicated by the broken line in Fig. 1 


$$
i_{d}=\frac{\Psi_{a}}{2\left(L_{q}-L_{d}\right)}-\sqrt{\frac{\Psi_{a}^{2}}{4\left(L_{q}-L_{d}\right)^{2}}+i_{q}^{2}} \ldots \ldots \ldots
$$

This control method is applied in the speed region in which the induced voltage $V_{o}$ does not exceed the induced voltage limit $V_{\text {om }}$. In this case, point I in Fig. 1 is the operating point generating maximum torque by MTPA control considering the current limit. In this control region, the armature current $I_{a}$ is equal to the current limit $I_{a m}$, and the induced voltage $V_{o}$ is less than the induced voltage limit $V_{\text {om }}$.

2.2 Flux-weakening Control for Maximizing Torque

The induced voltage increases with increasing rotor speed. When the motor speed reaches the base speed, the induced voltage becomes equal to the induced voltage limit $V_{\text {om }}$. Hence, the induced voltage is controlled to the induced voltage limit $V_{o m}$ by flux-weakening (FW) control above the base speed, and the $d$-axis current is given by the following equation $^{(6)}$.

$$
i_{d}=\frac{1}{L_{d}}\left\{\sqrt{\left(\frac{V_{o m}}{\omega}\right)^{2}-\left(L_{q} i_{q}\right)^{2}}-\Psi_{a}\right\} \cdots \cdots \cdots \cdots
$$

In the maximum output control, the current vector is controlled along the current limit circle indicated by arrow II in Fig. 1. In this control region, the induced voltage and current are equal to the induced voltage limit $V_{o m}$ and the current limit $I_{a m}$, respectively.

2.3 Maximum Torque per Flux Control In the case of operation along the current limit circle beyond the base speed, the operating limit occurs at the rotor speed at which the operating point is located at the intersection of the $d$-axis and the current limiting circle. If $\Psi_{d \min }\left(=\Psi_{a}-L_{d} I_{a m}\right)<0$, the operation of MTPF control can be applied to an IPMSM. Hence, the operating region of the IPMSM can be expanded by operating along the MTPF curve, as indicated by arrow III in Fig. 1. However, the algorithm to determine the operating point of MTPF control is complex ${ }^{(3)}$.

Hence, this paper proposes a method for generating the current command value using a straight-line approximation of the MTPF curve. A straight-line approximation of the MTPF curve is determined to be an accurate approximation of the actual operating region using the least-squares method. The maximum speed of the IPMSM listed in Table 1 is $2,000 \mathrm{r} / \mathrm{min}$ in this paper, and the following approximation expression of the MTPF curve was obtained.

$$
i_{d}=-4.425 i_{q}-0.761 \ldots \ldots \ldots \ldots \ldots \ldots \ldots \ldots \ldots
$$

Figure 3 shows the torque versus speed characteristics based on several control methods. This figure indicates that operation over a wide speed region is possible by appropriately switching the maximum output control. In addition, this figure clarifies that the approximation error of MTPF control in the actual operating region is minimized by accurate approximation of the linear region. Therefore MTPF control can be achieved by applying the proposed method using the straight-line approximation, and the control algorithm becomes simple.

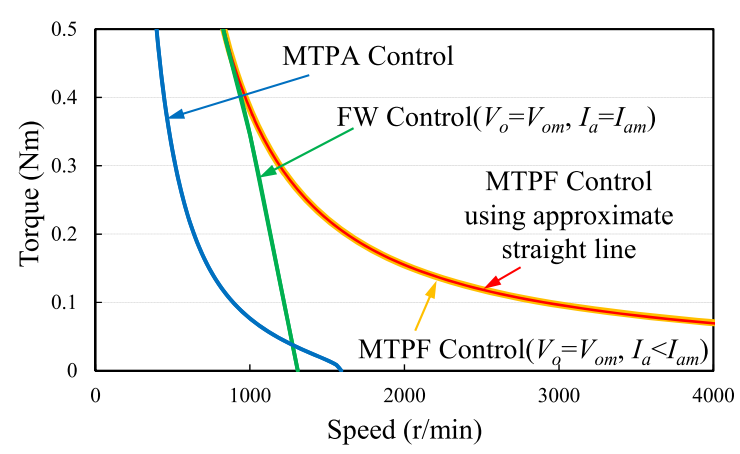

Fig. 3. Torque vs. speed characteristics based on several control methods

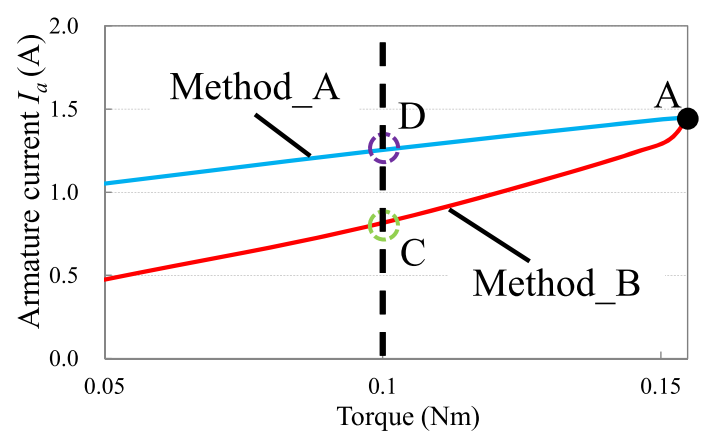

Fig. 4. Comparison of armature current corresponding to Method_A and Method_B at 2,000 r/min

\section{Control Method in Flux-weakening Region}

3.1 Current Vector Generation Method in Fluxweakening Region In a high-speed region in which the MTPF control should be applied to obtain the maximum output, we discuss the current vector generation method under a light-load.

In the first method, the operation of the current vector along the MTPF approximation inside the constant-voltage ellipse is considered. This method is referred to herein as Method_A. Hence, the operating point is present inside a constant-voltage ellipse, and the induced voltage $V_{o}$ is less than the limit voltage $V_{o m}$. For example, point $\mathrm{D}$ in Fig. 2 corresponds to the operating point at a load torque of $0.1 \mathrm{Nm}$. In the second method, the operation of current vector along the constant-voltage ellipse is considered. This method is referred to herein as Method_B. In this method, the current vector is operated at the intersection of the constantvoltage ellipse and the constant-torque curve. Point $\mathrm{C}$ in Fig. 2 corresponds to the operating point at a load torque of $0.1 \mathrm{Nm}$. Method_B appears to be more efficient compared to Method_A because the copper loss decreases with decreasing current. Figure 4 shows the armature current versus torque characteristics at 2,000 r/min under the control of Method_A and Method_B. This figure shows that Method_B can reduce the armature current compared to Method_A. Therefore, Method_B is applied as the current vector generation method in the proposed IPMSM control system.

3.2 Generation of Current Commands Figure 5(a) shows the general method for generating the $d$ - and $q$-axis current commands. In this method, $q$-axis current command $i_{q}{ }^{*}$ is determined by the speed error $\Delta \omega$. Then, the $d$-axis current command $i_{d}{ }^{*}$ is determined using the current vector control algorithms given by (3), (4) and (5). The $i_{q \text { limit }}$ in Fig. 5(a) 


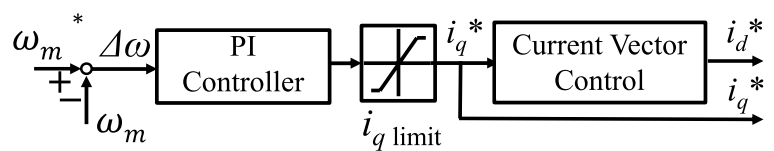

(a) Generation of current commands based on $q$-axis current command.

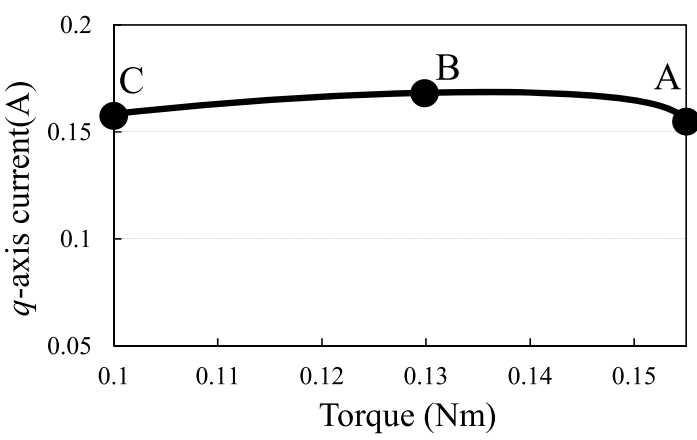

(b) $q$-axis current vs. torque characteristics $(2,000 \mathrm{r} / \mathrm{min})$.

Fig. 5. Operation along constant voltage ellipse (Conventional method.)

represents a limit value of the $q$-axis current command $i_{q}{ }^{*}$. The value of $i_{q \text { limit }}$ is determined based on the $q$-axis current during the maximum output control shown in Fig. 1. The current limit $i_{\text {qlimit }}$ is decreased with increasing rotor speed in order to control the induced voltage $V_{o}$ and the armature current $I_{a}$ to the induced voltage limit $V_{o m}$ and the armature current limit $I_{a m}$, respectively.

In the proposed current vector generation method (Method_B), the current vector moves from point A toward B and $\mathrm{C}$ at $2000 \mathrm{r} / \mathrm{min}$ as the load torque decreases, as shown in Fig. 2. In this case, the $q$-axis current must increase from point A to point B. Figure 5(b) shows the $q$-axis current vs. torque characteristics. Points $\mathrm{A}, \mathrm{B}$, and $\mathrm{C}$ correspond to operating points $\mathrm{A}, \mathrm{B}$, and $\mathrm{C}$ in Fig. 2. The MTPF control is switched to operation along the constant-voltage ellipse at point $\mathrm{A}$. Point $\mathrm{C}$ is the operating point at a load torque of $0.1 \mathrm{Nm}$. This figure shows that the $q$-axis current hardly changes for a change of the torque, and thus torque control by the $q$-axis current seems difficult. Moreover, the $q$-axis current must increase in order to decrease the torque in the region from point $\mathrm{A}$ to point $\mathrm{B}$. In the conventional system shown in Fig. 5(a), however, the $q$-axis current command decreases when the output of PI controller decreases. Therefore, stable operation cannot be achieved by the conventional method shown in Fig. 5(a).

The proposed current command generation method based on armature current command is shown in Fig. 6(a). In the proposed method, an armature current command $I_{a}{ }^{*}$ is first generated from $\Delta \omega$, and the current phase angle $\beta^{*}$ corresponding to the current command $I_{a}{ }^{*}$ is then determined using Eqs. (6) and (7). Equation (6) is used to achieve the MTPA control ${ }^{(3)}$, and Eq. (7) was derived from condition of $V_{o}=V_{o m}$ and Eqs. (1), (8) and (9). Equation (7) is used in the speed range above the base speed including MTPF control region. Based on $I_{a}{ }^{*}$ and $\beta^{*}$, the $d$ - and $q$-axis current commands are determined using Eqs. (8) and (9).

$$
\beta_{-M T P A}^{*}=\sin ^{-1} \frac{-\Psi_{a}+\sqrt{\Psi_{a}^{2}+8\left(L_{q}-L_{d}\right)^{2} I_{a}{ }^{* 2}}}{4\left(L_{q}-L_{d}\right) I_{a}{ }^{*}}
$$

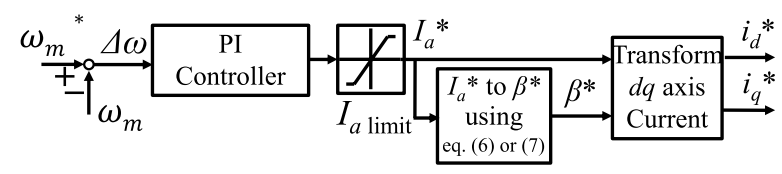

(a) Generation of current commands based on armature current command.

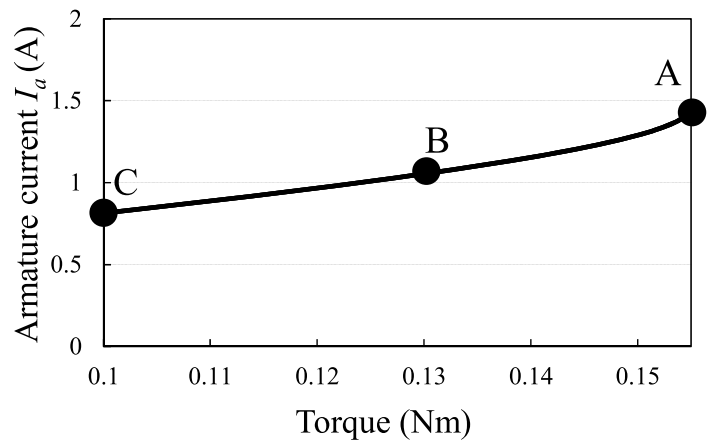

(b) Armature current vs. torque characteristics $(2,000 \mathrm{r} / \mathrm{min})$.

Fig. 6. Operation along constant voltage ellipse (Proposed method)

$$
\begin{aligned}
& \beta_{-F W}^{*}=\sin ^{-1} \frac{L_{d} \Psi_{a}+\sqrt{\left(L_{d} \Psi_{a}\right)^{2}-\left(L_{d}^{2}-L_{q}^{2}\right)\left(\Psi_{a}^{2}+\left(L_{q} I_{a}{ }^{*}\right)^{2}-\left(\frac{V_{o m}}{\omega}\right)^{2}\right)}}{\left(L_{d}^{2}-L_{q}^{2}\right) I_{a}{ }^{*}} \\
& \text {............. (7) } \\
& i_{q}^{*}=I_{a}^{*} \cos \beta^{*} \\
& i_{d}^{*}=-I_{a}^{*} \sin \beta^{*}
\end{aligned}
$$

Figure 6(b) shows the armature current vs. torque characteristics at 2,000 r/min. In the operation along the constantvoltage ellipse, the output torque increases with increasing armature current. Therefore, stable operation can be achieved by the proposed method shown in Fig. 6(a). However, if the armature current becomes greater than the current at the intersection point of the constant-voltage ellipse and the MTPF curve (the point $\mathrm{A}$ in Fig. 2), the torque decreases with increasing armature current in the operation along the constant voltage ellipse. Thus, the limitation of the armature current is necessity. The $I_{a \text { limit }}$ in Fig. 6(a) represents a limit value of the armature current command $I_{a}{ }^{*}$, and is determined based on the armature current during the maximum output control. $I_{a \text { limit }}$ is set to $I_{a m}$ below the speed at which the current vector control method is changed from FW control to MTPF control under the maximum output control shown in Sect. 2. Above that speed, $I_{a \text { limit }}$ is determined by the current at the intersection point of the constant-voltage ellipse and the MTPF curve given by Eq. (5), and $I_{a \text { limit }}$ is decreased with the increasing rotor speed.

\section{Analysis Results}

The analysis is carried out using the parameters listed in Table 1. The analysis results show the acceleration characteristics, where the speed command steps up from 100 to $2,000 \mathrm{r} / \mathrm{min}$ under $0.1 \mathrm{Nm}$. Figure 7 shows the responses of the rotor speed, torque and armature current controlled by Method_A and Method_B. The rotor speed and torque of Method_A and Method_B are approximately the same. However, the armature current of Method_B is less than that of Method_A after the speed reaches the commanded speed. Figure 8 shows the current vector trajectory under 


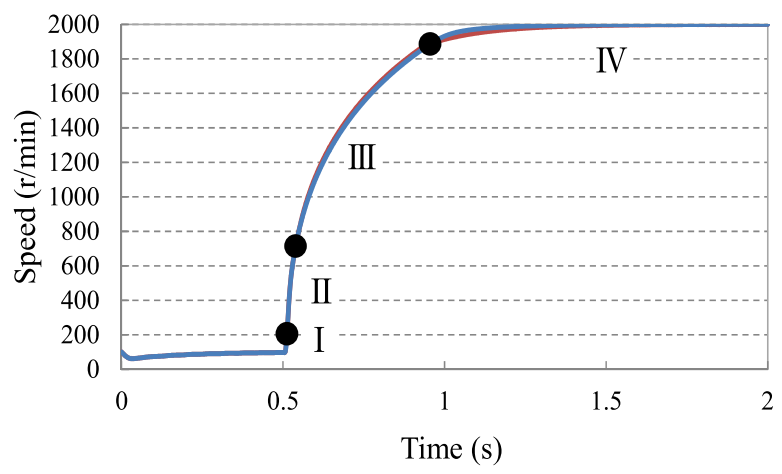

(a) Speed characteristics.

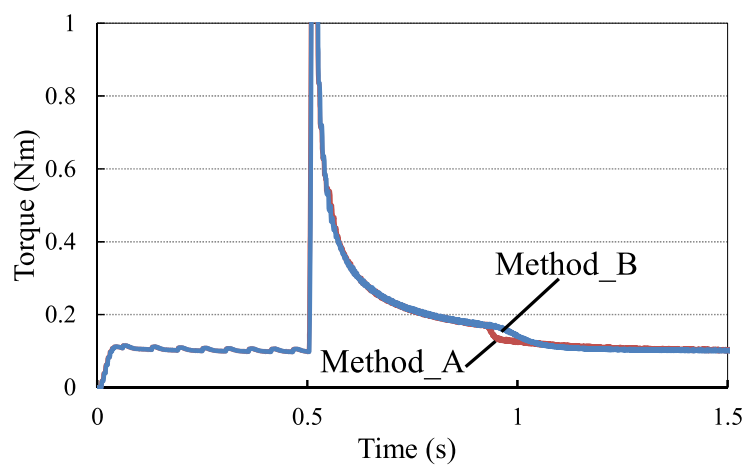

(b) Torque characteristics.

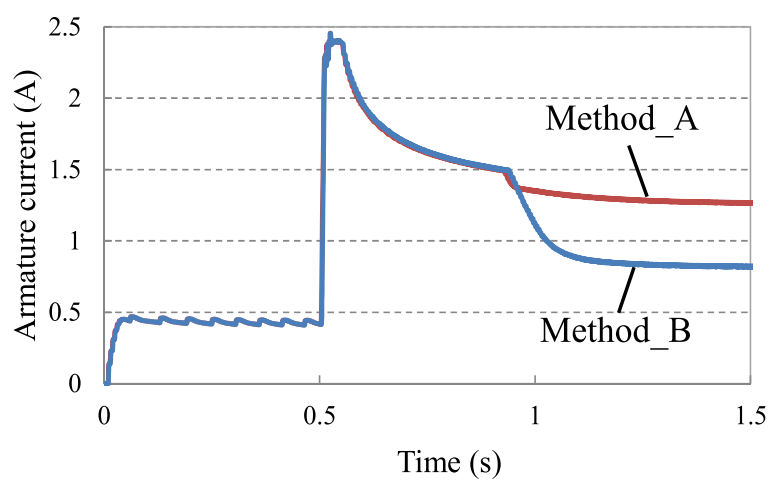

(c) Armature current characteristics.

Fig. 7. Characteristics of Method_A and Method_B

the operation shown in Fig. 7. Figure 8(a) shows that the operation along the straight-line approximation of the MTPF curve is possible using the Method_A. Figure 8(b) shows that operation along the constant-voltage ellipse is possible using the Method_B after the speed reaches the commanded speed. The current vector trajectory seems not to be along the MTPA curve in Fig. 8. This trajectory represents the momentary response of controlled current vector at step change of speed command, at which the current vector command also instantaneously changes to the operating point I in Fig. 8. Therefore, there is no necessity that current vector moves along the MTPA curve at this transient-state.

Figure 9 shows the torque controlled by the proposed method under the operation conditions shown in Fig. 7. Figure 9 also shows the theoretical value for each control method. The output torque was not observed to differ between the calculated value and the theoretical value in the region which is used in actual operation. Therefore, the good current vector control and speed control is achieved by the proposed control method.

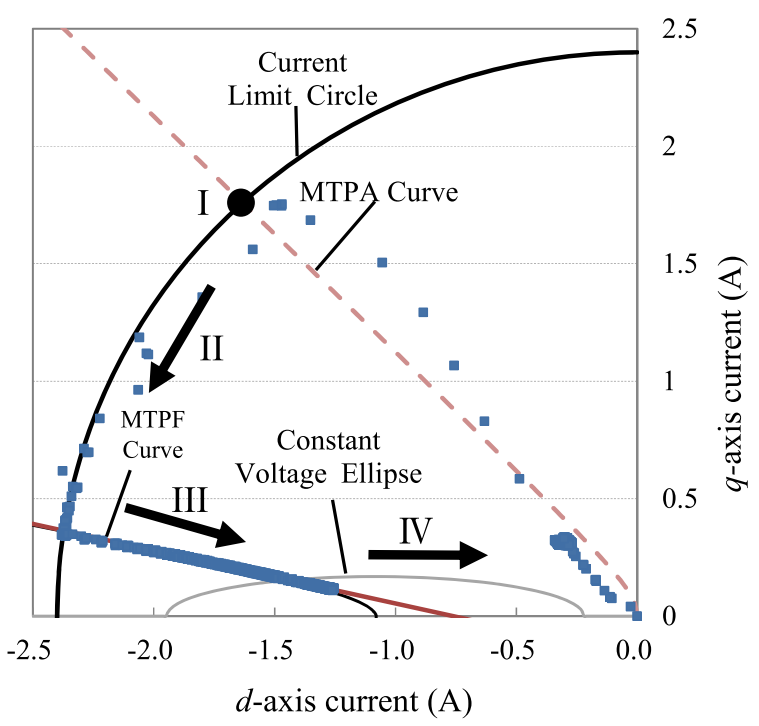

(a) Method_A.

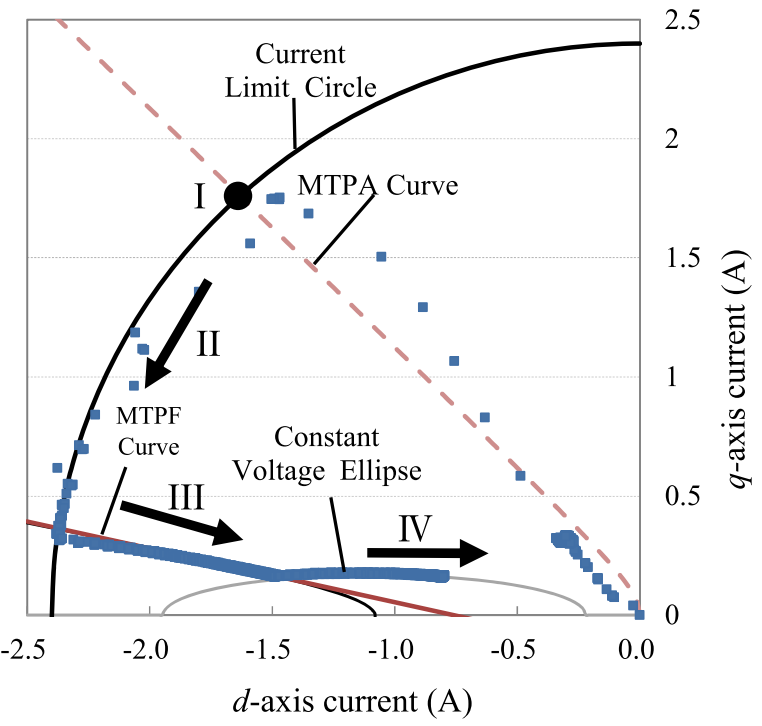

(b) Method_B.

Fig. 8. Current vector trajectory

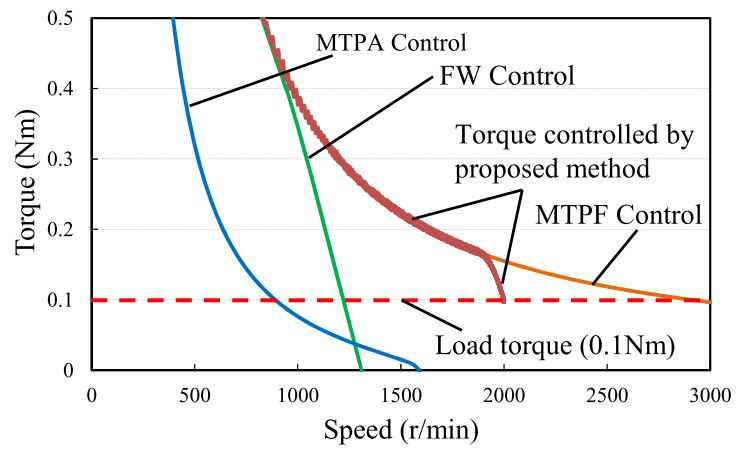

Fig. 9. Torque corresponding to the rotor speed

Based on the analysis results, the following results were obtained. The MTPF control is possible using the straightline approximation of the MTPF curve. Operation using Method_B is more efficient compared to that using Method_A under a light-load. The stable operation can be achieved by using the armature current value and current phase angle to generate the $d$ - and $q$-axis current commands. 


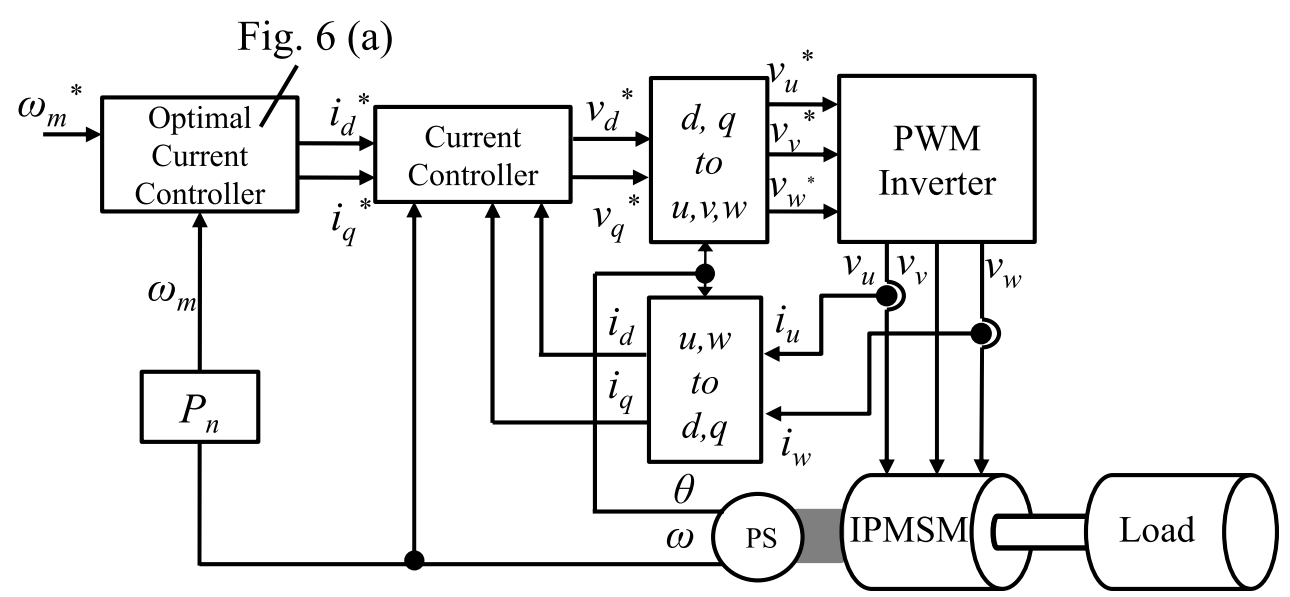

Fig. 10. IPMSM drive system based on current vector control

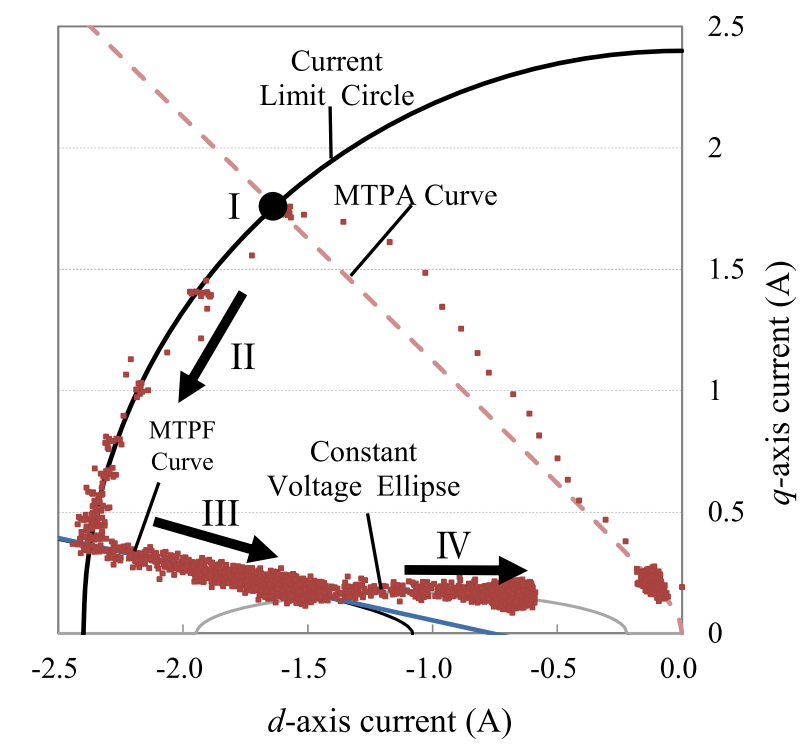

Fig. 11. Current vector trajectory $(2,000 \mathrm{r} / \mathrm{min})$

\section{Experimental Results}

5.1 Transient Characteristics The experiment is carried out under same conditions as the analysis. The purpose of the experiment is to realize efficient operation along the constant-voltage ellipse and MTPF control in the highspeed region. Figure 10 shows the IPMSM drive system used in the experiment. The experimental results reveal the acceleration characteristics, where the speed command steps up from 100 to $2,000 \mathrm{r} / \mathrm{min}$ under $0.1 \mathrm{Nm}$. Figure 11 shows the measured current vector trajectory. The three control methods are confirmed to switch properly with increasing rotor speed. Figure 12 shows the speed response characteristic, and the desirable speed response is realized. The results of the experiment and analysis are confirmed to be similar.

5.2 Motor Losses The motor losses of Method_A and B under the high-speed, light-load condition are compared. Figure 13 shows characteristics of copper and iron losses at $2,000 \mathrm{r} / \mathrm{min}$. This tested condition is the same as in Fig. 4. The magnetic saturation is not considered in the simulations, and thus the $d$ - and $q$-axis inductances are set to the constant values at rated current as shown in Table 1. However, the

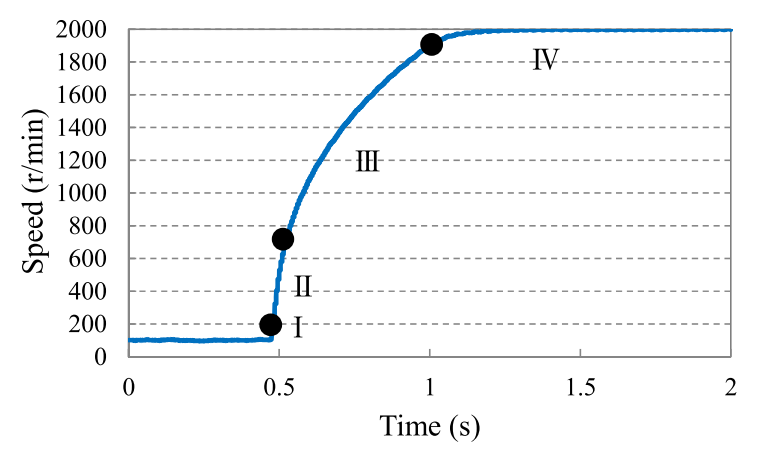

Fig. 12. Speed responses

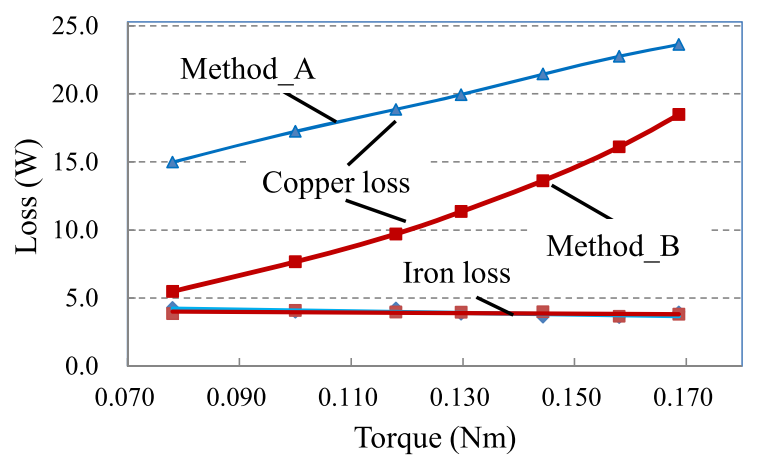

Fig. 13. Motor losses

magnetic saturation exists in the tested motor and thus the $q$-axis inductance increases in the high-speed flux weakening region because the $q$-axis current becomes small. As a result, the current to produce the same torque becomes less than Fig. 4 in the experiment because of increase of reluctance torque. The current of Method B becomes smaller than Method A at the torque of $0.17 \mathrm{Nm}$, and the copper loss has become small as shown in Fig. 13, even if the armature current is the same at torque of $0.16 \mathrm{Nm}$ in Fig. 4. Additionally, the difference of copper loss increases with decreasing the load torque. On the other hand, iron loss of the Method_A and $\mathrm{B}$ is almost same irrespective of torque value. It is confirmed that Method_B is more efficient under the high-speed, light-load condition.

\section{Conclusions}

A novel control method for use in the flux-weakening re- 
gion for operation at optimal torque point has been proposed. The simulation and experimental results confirmed the possibility of expanding the operation region by applying the simplified control method using approximate MTPF control algorithm. In addition, efficient operation is possible using Method_B. The stable operation can be achieved by using the armature current value and current phase angle to generate the $d$ - and $q$-axis current commands. Thus, wide, efficient and stable operation is possible by the proposed control method. In order to utilize the available voltage as much as possible and improve the control accuracy, the current vector control to keep $V_{a}$ to $V_{a m}$ and the consideration of magnetic saturation are required. We will continue study for these improvements.

\section{References}

( 1 ) S. Morimoto: "Trend of permanent magnet synchronous machines", IEEJ Trans. Inst. Elect. Eng., No.2, pp.101-108 (2007)

(2) R.F. Schiferl and T.A. Lipo: "Power capability of salient pole permanent magnet synchronous motors in variable speed drive applications", IEEE Trans. Ind. Appl., Vol.26, pp.115-123 (1990)

( 3 ) S. Morimoto, Y. Takeda, T. Hirasa, and K. Taniguchi: "Expansion of operating limits for permanent magnet motor by current vector control considering inverter capacity", IEEE Trans. Ind. Appl., Vol.29, pp.866-871 (1990)

( 4 ) B. Sneyers, D.W. Novotny, and T.A. Lipo: "Field-weakening in buried permanent magnet ac motor drives", IEEE Trans. Ind. Appl., Vol.1A-21, pp.398407 (1985)

( 5 ) T.M. Jahns: "Flux-weakening regime operation of an interior permanentmagnet synchronous motor drive", IEEE Trans. Ind. Appl., Vol.1A-23, pp.681-689 (1987)

( 6 ) S. Morimoto, M. Sanada, and Y. Takeda: "Wide-speed operation of interior permanent magnet synchronous motors with high-performance current regulator", IEEE Trans. Ind. Appl., Vol.30, No.4, pp.920-926 (1994)

( 7 ) P. Guglielmi, B. Boazzo, E. Armando, G. Pellegrino, and A. Vagati: "Magnet minimization in IPM-PMASR motor design for wide speed range application”, in Proc. IEEE ECCE., pp.4201-4207 (2011)

( 8 ) S. Ooi, S. Morimoto, M. Sanada, and Y. Inoue: "Performance evaluation of a high-power-density PMASynRM with ferrite magnets", IEEE Trans. Ind. Appl., Vol.49, No.3, pp.1308-1314 (2013)

( 9 ) S. Morimoto, Y. Asano, T. Kosaka, and Y. Enomoto: "Recent technical trends in PMSM", Int. Power. Electron. Conf., pp.1997-2003 (2014)

(10) T. Kato, N. Limsuwan, C.Y. Yu, K. Akatsu, and R.D. Lorenz: "Rare earth reduction using a novel variable magnetomotive force flux-intensified IPM machine", IEEE Trans. Ind. Appl., Vol.50, No.3, pp.1748-1756 (2014)

(11) H. Liu, Z.Q. Zhu, E. Mohamed, Y. Fu, and X. Qi: "Flux-weakening control of nonsalient pole PMSM having large winding inductance, accounting for resistive voltage drop and inverter nonlinearities", IEEE Trans. Power. Electron., Vol.27, No.2, pp.942-950 (2012)

(12) G.G. Lopez, F.S. Gunawan, and J.E. Walters: "Optimum torque control of permanent-magnet AC machines in the field-weakened region", IEEE Trans. Ind. Appl., Vol.41, No.4, pp.1020-1028 (2005)

(13) G. Pellegrino, E. Armando, and P. Guglielmi: "Direct-flux vector control of IPM motor drives in the maximum torque per voltage speed range", IEEE Trans. Ind. Electron., Vol.59, No.10, pp.3780-3788 (2012)
(14) K. Ueda, S. Morimoto, Y. Inoue, and M. Sanada: "A novel control method in flux-weakening region for efficient operation of interior permanent magnet synchronous motor", Int. Power. Electron. Conf., pp.312-317 (2014)

Keitaro Ueda (Student Member) received the B.E. degree from Kobe

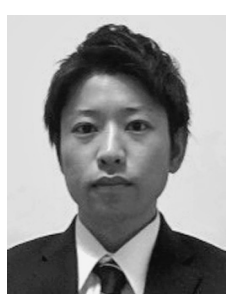
City College of Technology, Kobe, Japan, in 2013, and the M.E. degree from Osaka Prefecture University, Sakai, Japan, in 2015. He was involved in the study on the control of permanent magnet synchronous motor at Osaka Prefecture University. He is currently with Mitsubishi Electric Corporation, Tokyo, Japan.

Shigeo Morimoto (Senior Member) received the B.E., M.E., and

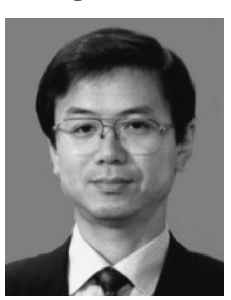
Ph.D. degrees from Osaka Prefecture University, Sakai, Japan, in 1982, 1984, and 1990, respectively. In 1984, he joined Mitsubishi Electric Corporation, Tokyo, Japan. Since 1988, he has been with the Graduate School of Engineering, Osaka Prefecture University, where he is currently a Professor. His main areas of research interest are permanent magnet synchronous machines, reluctance machines and their control systems. Dr. Morimoto is a member of the IEEE, the Society of Instrument and Control Engineers of Japan, the Institute of Systems, Control and Information Engineers, and the Japan Institute of Power Electronics.

Yukinori Inoue (Member) received the B.E., M.E., and Ph.D. degrees

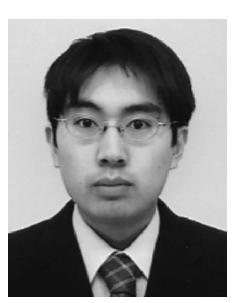
from Osaka Prefecture University, Sakai, Japan, in 2005, 2007, and 2010, respectively. Since 2010, he has been with the Graduate School of Engineering, Osaka Prefecture University, where he is currently an Assistant Professor. His research interests include control of electrical drives, in particular, the direct torque control of permanent magnet synchronous motors and position sensorless control of these motors. Dr. Inoue is a member of the IEEE and the Japan Institute of Power Electronics.

Masayuki Sanada (Senior Member) received the B.E., M.E., and

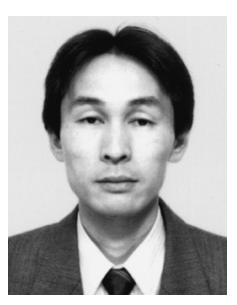
Ph.D. degrees from Osaka Prefecture University, Sakai, Japan, in 1989, 1991, and 1994, respectively. Since 1994, he has been with the Graduate School of Engineering, Osaka Prefecture University, where he is currently an Associate Professor. His main areas of research interest are permanent-magnet motors for direct-drive applications, their control systems, and magnetic field analysis. Dr. Sanada is a member of the IEEE, the Japan Institute of Power Electronics, and the Japan Society of Applied Electromagnetics and Mechanics. 